7. Kirby T. Evidence mounts on the disproportionate effect of COVID-19 on ethnic minorities. Lancet Respir Med 2020 May 10 [Epub ahead of print]. doi: 10.1016/S2213-2600(20)30228-9.

8. Ma Y, Xu Q, Wang F et al. Characteristics of asymptomatic patients with SARS-CoV-2 infection in Jinan, China. Microbes Infect 2020;22:212-217.
9. Day M. COVID-19: identifying and isolating asymptomatic people helped eliminate virus in Italian village. $B M J$ 2020;368:m1165. doi: 10.1136/bmj. m1165.

\title{
Utility of asymptomatic inpatient testing for COVID-19 in a low-prevalence setting: A multicenter point-prevalence study
}

\author{
Anthony D. Bai MD ${ }^{1}$, , Xena X. Li MD¹, Mohammed Alsalem MD, Sarah Khan MD², Marek Smieja MD³, Dominik Mertz MD \\ and Zain Chagla MD ${ }^{5}$ \\ ${ }^{1}$ Division of Infectious Diseases, McMaster University, Hamilton, Ontario, Canada, ${ }^{2}$ Infection Prevention Control, McMaster Children's Hospital, Hamilton, Ontario, \\ Canada, ${ }^{3}$ Laboratory Medicine, St Joseph's Healthcare Hamilton and Hamilton Health Sciences, Hamilton, Ontario, Canada, ${ }^{4}$ Infection Control, Hamilton Health \\ Sciences, Hamilton, Ontario, Canada and ${ }^{5}$ Infection Control, St. Joseph's Healthcare Hamilton, Hamilton, Ontario, Canada
}

For coronavirus disease 2019 (COVID-19), frequently reported symptoms in nonseverely sick patients include fever, fatigue, and dry cough. ${ }^{1}$ However, infected patients may not exhibit symptoms. Some patients may be presymptomatic and develop symptoms later in the disease course whereas others remain asymptomatic, but either group can be infectious. ${ }^{2,3}$

Hence, asymptomatic carriers and presymptomatic individuals may be potential sources of nosocomial transmission. As such, consideration can be given to testing asymptomatic patients upon admission to the hospital. The Infectious Diseases Society of America (IDSA) guidelines on the diagnosis of COVID-19 recommend against testing of asymptomatic hospitalized patients in lowprevalence $(<2 \%)$ settings. ${ }^{4}$ This recommendation is based on expert opinion and lacks supporting evidence.

The city of Hamilton, Ontario, Canada, has a population of 580,000 and qualified as a low-prevalence area at the time of this study. The average number of daily new cases identified was 1.9 per 100,000 population. ${ }^{5}$ For hospital admission, the testing strategy was (and continues to be) based on symptoms or exposures. ${ }^{6}$ Within this low-prevalence setting, we conducted a multicenter point-prevalence study to evaluate the utility of severe acute respiratory coronavirus virus 2 (SARS-CoV-2) testing of asymptomatic patients in terms of capturing positive cases that would be missed by symptom-based testing on admission.

\section{Methods}

We conducted a point-prevalence study across 4 tertiary acute-care hospitals in Hamilton from April 15 to April 21, 2020. The Hamilton Integrated Research Ethics Board approved this study (no. 10894).

\section{COVID-19 testing on admission}

According to provincial guidelines, testing was based on the following symptoms: fever, new or worsening acute respiratory illness symptom (ie, cough, dyspnea, sore throat, runny nose or sneezing, nasal congestion, hoarse voice, difficulty swallowing, new

Author for correspondence: Anthony D. Bai, E-mail: anthony.bai@medportal.ca Cite this article: Bai AD, et al. (2020). Utility of asymptomatic inpatient testing for COVID-19 in a low-prevalence setting: A multicenter point-prevalence study. Infection Control \& Hospital Epidemiology, 41: 1233-1235, https://doi.org/10.1017/ice.2020.349 olfactory or taste disorder(s), nausea or vomiting, diarrhea, abdominal pain), or clinical or radiological evidence of pneumonia. ${ }^{6}$ Atypical presentations included unexplained fatigue or malaise, delirium, falls, acute functional decline, exacerbation of chronic conditions, chills, headache, croup, tachycardia, decrease in blood pressure, hypoxia, and lethargy. ${ }^{6}$ At the time of this study, a patient with any of the above symptoms or exposure underwent nasopharyngeal swab testing for SARS-CoV-2 upon admission to the hospital. ${ }^{6}$

\section{Patient inclusion}

On the point-prevalence testing date, all adult inpatients were tested once if they were admitted for 7-14 days, regardless of symptoms or prior negative SARS-CoV-2 test result. Patients with a known positive SARS-CoV-2 test were excluded.

Testing on days 7-14 was based on the estimated median incubation period of 4 days (interquartile range, $2-7$ days). ${ }^{7}$ Testing after the median incubation period would have captured most COVID-19 cases, even if the exposure occurred as late as the day of admission.

\section{Testing procedure}

The nasopharyngeal swabs were collected, and a polymerase-chain reaction assay for the SARS-CoV-2 envelope and 5'-untranslated region genes was performed at the local virology laboratory in the hospital. This assay was validated against the provincial standard testing.

\section{Data collection}

Data were extracted from the patient electronic chart system, which included demographics, admitting diagnosis, hospital location, admitting service, reason for admission, Charlson comorbidity index, ${ }^{8}$ prior SARS-CoV-2 test result, chest imaging, and other microbiology test results. On the day of testing, patients were assessed for symptoms, as listed above. ${ }^{6}$

\section{Results}

Across the 4 hospitals, 125 inpatients were tested for SARS-CoV-2 (Table 1). Also, 5 patients (4.0\%) had fever and 3 patients (2.4\%) had respiratory symptoms at the time of their test. 
Table 1. Patient Characteristics

\begin{tabular}{|c|c|}
\hline Characteristic & $\begin{array}{l}\text { Patients Tested } \\
\quad(\mathrm{N}=125), \\
\text { No. }(\%)^{\mathrm{a}}\end{array}$ \\
\hline \multicolumn{2}{|l|}{ Demographics } \\
\hline Age, median y (IQR) & $77.0(65.0-84.0)$ \\
\hline Male & $58(46.4)$ \\
\hline \multicolumn{2}{|l|}{ Location prior to admission } \\
\hline Community & $94(75.2)$ \\
\hline Hospital & $16(12.8)$ \\
\hline Retirement home & $11(8.8)$ \\
\hline Long term care home & $4(3.2)$ \\
\hline \multicolumn{2}{|l|}{ Hospitals $^{b}$} \\
\hline A & $52(41.6)$ \\
\hline B & $30(24.0)$ \\
\hline C & $29(23.2)$ \\
\hline $\mathrm{D}$ & $14(11.2)$ \\
\hline \multicolumn{2}{|l|}{ Location within hospital } \\
\hline Ward & $95(76.0)$ \\
\hline ICU & $8(6.4)$ \\
\hline $\begin{array}{l}\text { Rehabilitation, palliative, or } \\
\text { chronic care }\end{array}$ & $22(17.6)$ \\
\hline \multicolumn{2}{|l|}{ Admitting service } \\
\hline Medicine & $49(39.2)$ \\
\hline Surgery & $30(24.0)$ \\
\hline $\begin{array}{l}\text { Hematology oncology, medical } \\
\text { oncology }\end{array}$ & $16(12.8)$ \\
\hline ICU & $8(6.4)$ \\
\hline Obstetrics & $1(0.8)$ \\
\hline Other & $21(16.8)$ \\
\hline \multicolumn{2}{|l|}{ Most common reason for admission } \\
\hline Hip fracture & $11(8.8)$ \\
\hline Solid tumor-related complication & $11(8.8)$ \\
\hline Stroke & $7(5.6)$ \\
\hline Weakness or fall & $7(5.6)$ \\
\hline Delirium or confusion & $7(5.6)$ \\
\hline \multicolumn{2}{|l|}{ Charlson comorbidity index } \\
\hline 0 & $18(14.4)$ \\
\hline 1 & $15(12.0)$ \\
\hline 2 & $28(22.4)$ \\
\hline 3 & $18(14.4)$ \\
\hline$\geq 4$ & $46(36.8)$ \\
\hline Immunosuppressed $^{c}$ & $21(16.8)$ \\
\hline \multicolumn{2}{|l|}{ Symptoms at testing } \\
\hline Fever & $5(4.0)$ \\
\hline Respiratory symptoms & $3(2.4)$ \\
\hline $\begin{array}{l}\text { Clinical or radiographic features } \\
\text { of pneumonia }\end{array}$ & $14(11.2)$ \\
\hline Atypical symptoms & $10(8.0 \%)$ \\
\hline
\end{tabular}

Table 1. (Continued)

\begin{tabular}{|c|c|}
\hline Characteristic & $\begin{array}{l}\text { Patients Tested } \\
\qquad(\mathrm{N}=125), \\
\text { No. }(\%)^{\mathrm{a}}\end{array}$ \\
\hline \multicolumn{2}{|l|}{ Chest imaging } \\
\hline Chest X-ray & $92(73.6)$ \\
\hline CT chest image & $26(20.8)$ \\
\hline \multicolumn{2}{|l|}{ Last chest imaging findings } \\
\hline Consolidation & $34(27.2)$ \\
\hline Intralobular lines & $1(0.8)$ \\
\hline Organizing pneumonia & $0(0)$ \\
\hline Days from admission to testing, median (IQR) & $11.0(9.0-13.0)$ \\
\hline \multicolumn{2}{|l|}{ SARS-CoV-2 test result } \\
\hline Negative & $124(99.2)$ \\
\hline Positive & $1(0.8)$ \\
\hline Prior SARS-CoV-2 testing done and negative & $85(68.0)$ \\
\hline Days from prior SARS-CoV-2 test to current test & $10.0(8.0-12.0)$ \\
\hline \multicolumn{2}{|l|}{ Testing for other respiratory viruses ${ }^{d}$} \\
\hline Negative & $86(68.8)$ \\
\hline Positive & $0(0)$ \\
\hline Not done & $39(31.2)$ \\
\hline
\end{tabular}

Note. IQR, interquartile range; ICU, intensive care unit; $\mathrm{CT}$, computed tomography. aUnits unless otherwise specified.

${ }^{\text {b}}$ The hospital sites include a 607-bed hospital that is the regional cardiac surgery and neurosurgery center; a 228-bed hospital that is the regional center for cancer care and bone marrow transplant; a 250-bed hospital that specializes in chronic care and rehabilitation; and a 426-bed hospital that specializes in dialysis and renal transplant.

Immunosuppression includes any of the following: chemotherapy, steroid therapy, neutropenia with absolute neutrophil count $<0.5$, active hematological malignancy, HIV, primary immunodeficiency, or solid organ or hematopoietic stem cell transplant requiring immunosuppressive therapy.

${ }^{d}$ Other respiratory viruses include influenza $A$ and $B$, respiratory syncytial virus (RSV), human metapneumovirus, parainfluenza virus types 1 and 3 , adenovirus, rhinovirus, and enterovirus.

Only 1 patient $(0.8 \%)$ was positive for SARS-CoV-2. This patient presented to hospital $\mathrm{C}$ reporting 2 weeks of fever and cough. A chest x-ray showed an ill-defined opacity in the left lower lobe. The patient was initially isolated for acute respiratory illness. Isolation was discontinued on admission day 2 after the SARSCoV-2 test came back negative, and the patient was treated for a presumptive bacterial pneumonia. The following day, the patient was transferred to hospital D. The positive point-prevalence test occurred on admission day 13 at hospital D. At the time of testing, the patient had no new symptoms and the patient's respiratory status continued to improve.

\section{Discussion}

In this point-prevalence study, 125 inpatients were tested, and only 1 patient $(0.8 \%)$ was positive for SARS-CoV-2. This positive case was symptomatic, and the patient had had a prior SARS-CoV-2 test that was likely a false negative. He was initially isolated for acute respiratory illness on presentation to the hospital. For COVID-19, infectiousness has been estimated to decline quickly within 7 days, ${ }^{9}$ so the patient was likely no longer infectious at the time of the second test. Therefore, asymptomatic testing 
did not add any useful information or change infection control practices compared to symptom-based screening.

To our knowledge, this is the first study to evaluate the benefit of asymptomatic testing for hospitalized patients in a low-prevalence setting. In a New York hospital, universal testing of women admitted for delivery showed $13.5 \%$ asymptomatic positive SARS-CoV-2 results. ${ }^{10}$ In contrast, our study found no asymptomatic positive cases. This finding is likely due to differences in local prevalence.

The strengths of our study include the systematic approach to testing. Also, the inclusion of 4 hospitals makes the results more generalizable. Our study has 2 limitations. First, repeated pointprevalence testing would have yielded more precise results, but this method would not have been feasible given the capacity of our virology laboratory. Second, nasopharyngeal swabbing may produce false-negative results, given its estimated sensitivity between $75 \%$ and $95 \%{ }^{4}$ Although imperfect, nasopharyngeal swabbing is practical and is currently the recommended test for asymptomatic patients. ${ }^{4}$

In conclusion, our study suggests the minimal utility of asymptomatic testing in hospitalized patients compared to symptom screening and targeted testing in low-prevalence settings, which supports the current IDSA guidelines. ${ }^{4}$

Acknowledgments. None.

Financial support. No financial support was provided relevant to this article.

\section{References}

1. Wang D, Hu B, Hu C, et al. Clinical characteristics of 138 hospitalized patients with 2019 novel coronavirus-infected pneumonia in Wuhan, China. JAMA 2020;323:1061-1069.

2. Kimball A, Hatfield KM, Arons M, et al. Asymptomatic and presymptomatic SARS-CoV-2 infections in residents of a long-term care skilled nursing facility-King County, Washington, March 2020. Morb Mortal Wkly Rept 2020;69:377.

3. Bai Y, Yao L, Wei T, et al. Presumed asymptomatic carrier transmission of COVID-19. JAMA 2020;323:1406-1407.

4. Hanson KE, Caliendo AM, Arias CA, et al. IDSA guidelines on the diagnosis of COVID-19. Infectious Diseases Society of America website. https://www. idsociety.org/practice-guideline/covid-19-guideline-diagnostics/. Published May 6, 2020. Accessed July 20, 2020.

5. Status of cases in Hamilton. City of Hamilton website. https://www. hamilton.ca/coronavirus/status-cases-in-hamilton. Accessed June 3, 2020.

6. COVID-19 provincial testing guidance update, April 8, 2020. Ministry of Health Ontario website. http://www.health.gov.on.ca/en/pro/programs/ publichealth/coronavirus/docs/2019_covid_testing_guidance.pdf. Published April 8, 2020. Accessed April 13, 2020.

7. Guan WJ, Ni ZY, Hu Y, et al. Clinical characteristics of coronavirus disease 2019 in China. N Engl J Med 2020;382:1708-1720.

8. Charlson ME, Pompei P, Ales KL, MacKenzie CR. A new method of classifying prognostic comorbidity in longitudinal studies: development and validation. J Chronic Dis 1987;40:373-383.

9. He X, Lau EH, Wu P, et al. Temporal dynamics in viral shedding and transmissibility of COVID-19. Nat Med 2020;26:672-675.

10. Sutton D, Fuchs K, D'alton M, Goffman D. Universal screening for SARS-CoV-2 in women admitted for delivery. $N$ Engl J Med Published April 13, 2020. Accessed July 20, 2020. article.

\title{
Prolonged shedding of severe acute respiratory coronavirus virus 2 (SARS-CoV-2) RNA among patients with coronavirus disease 2019 (COVID-19)
}

\author{
Jessica P. Ridgway MD, MS ${ }^{1}$ (D), Nirav S. Shah MD, MPH ${ }^{2}$ and Ari A. Robicsek MD ${ }^{3}$ \\ ${ }^{1}$ Department of Medicine, University of Chicago, Chicago, Illinois, ${ }^{2}$ NorthShore University HealthSystem, Evanston, Ilinois and ${ }^{3}$ Providence St. Joseph Health, \\ Renton, Washington
}

Early reports from China indicate that severe acute respiratory coronavirus virus 2 (SARS-CoV-2) RNA may persist in the respiratory tracts of patients with coronavirus disease 2019 (COVID-19) for several weeks after symptom onset. ${ }^{1-3}$ However, the duration of SARS-CoV-2 RNA shedding has not been systematically studied in a large cohort of patients.

\section{Methods}

To estimate the duration of SARS-CoV-2 RNA shedding, we conducted a multisite study among patients who had nasopharyngeal

\footnotetext{
Author for correspondence: Jessica Ridgway, E-mail: Jessica.ridgway@uchospitals.edu Cite this article: Ridgway JP, Shah NS, and Robicsek AA. (2020). Prolonged shedding of severe acute respiratory coronavirus virus 2 (SARS-CoV-2) RNA among patients with coronavirus disease 2019 (COVID-19). Infection Control \& Hospital Epidemiology, 41: 1235-1236, https://doi.org/10.1017/ice.2020.307
}

specimens tested for SARS-CoV-2 RNA via real-time polymerase chain reaction (PCR) assay at Providence St Joseph Health (a 51-hospital healthcare organization based in Renton, Washington), University of Chicago Medicine in Chicago, Illinois, and NorthShore University HealthSystem (a 5-hospital healthcare system based in Evanston, Illinois). All patients with a positive SARS-CoV-2 PCR test between January 22, 2020, and April 23, 2020 who had at least 1 subsequent SARS-CoV-2 PCR test were included in the study. SARS-CoV-2 PCR tests were ordered at the discretion of medical providers at each institution. We calculated the percentage of patients with a persistent positive SARS-CoV-2 PCR test result up to 25 days after the first positive test. This study was approved by the institutional review board of each institution.

(C) 2020 by The Society for Healthcare Epidemiology of America. All rights reserved. This is an Open Access article, distributed under the terms of the Creative Commons Attribution licence (http://creativecommons.org/licenses/by/4.0/), which permits unrestricted re-use, distribution, and reproduction in any medium, provided the original work is properly cited. 